\title{
The Green Embankment: Using Afforestation as an Instrument Against Coastal Disasters
}

\author{
Ishrar Tabassum, Jay Andrew, Khalid Raihan Kabir
}

\begin{abstract}
In this article, the multifaceted linkages between environmental disasters, poverty and vulnerability is investigated through a case study carried out in one of the most remote areas of Bangladesh. Because of its geographical location, Bangladesh is dreadfully susceptible to disasters, such as cycles of flash floods, storm surges and cyclones. Afforestation is recommended as a means of embankment in the floodprone area. The authors therefore place conducted literature review on coastal afforestation as a sustainable option for protection against the natural hazards. Also, qualitative approaches, such as in-depth interviews, focus group discussions and observations were held for understanding people's responses to and the impact of a disaster in vulnerable sites. The field research compared a combination of participant observations and non-participant external interactions with coastal communities. The study shows afforestation as having great promise to not only be an effective method of protecting communities from major storm events, but also provide a steady flow of income to the struggling local economy. However, even though the system is relatively inexpensive, it is still a complicated system to run.
\end{abstract}

\section{Keywords: Afforestation; Embankments; Disaster;} Vulnerabilities.

\section{Introduction: Disasters around the world}

Not long ago, the greater part of the population in the world assumed that the disasters linked to floods, hurricane, cyclones, earthquakes and further natural hazards were caused due to natural disasters and it was established that their impact could be abridged through mitigation, preparedness and post-event humanitarian actions, but the focus even in much academic and policy work then was on the naturalness of the disasters [2].The current warming trend is of painstaking significance because most of it is extremely likely (greater than 95 percent probability) to be the result of anthropocentric activity since the mid- $20^{\text {th }}$ century because of the industrial revolution and proceeding at a rate that is unparalleled over decades to millennium. [9], [12], [14], [15].

\section{Bangladesh's Vulnerability}

Despite good advancement in cyclone and flood preparedness, exemplified by the existing comprehensive disaster management policies made by the Government of Bangladesh, localized vulnerability factors in cyclone hazards questionably hang about.

According to respondents, the vulnerabilities include:

- Vulnerability due to location and pattern of settlement

- Vulnerability due to inappropriate land management systems

- Vulnerability due to means of livelihood and a lack of infrastructure

- Vulnerability due to late responses to warnings and a complex decision making

\section{Effects of Embankments in Bangladesh}

The design and constructive methods of the earth embankments were not stable and alongside the erosive forces of water and the non-cooperation of the local people contributed to a high amount of instability. The underwater type embankments built on the eastern part were subjected to turbulent water current and changes in river courses. The estimate prepared by BWDB in 1984 showed that about $1200 \mathrm{~km}$ of bank length of rivers were subjected to erosion, 565 of which faced severe erosion problems [6].

a. Natural Forces in the way of Embankments:

Natural forces cause erosion of the embankments in the following way:

1. Rainfall Impact

2. Wave Impact

3. Turbulent water currents

4. Wind Impacts

\section{Afforestation as a defense mechanism in} Bangladesh

4.1 The EEA report 'Water-retention potential of Europe's forests' shows that water withholding plays an important role in buffering the effects of heavy rainfall and droughts. Forests can saturate up excess rainwater, preventing run-offs and harm from flooding. By releasing water in the dry season, forests can also help provide clean water and alleviate the effects of droughts. 
Partial yearly plantations of mangroves were undertaken on newly accreted land in the Patuakhali, Barisal, Noakhali and Chittagong coastal district in 1966.

\subsection{Species selection:}

Even though approximately 27 species of mangroves and a similar number of mangrove associates crop up in Bangladesh, most are rare, or of little economic importance [3], [8]. Merely 10 or so species arise frequently adequate to carry on silviculture. As a result of the early trial and error approach to plantations, only two species, Sonneratia apetala and Avicennia officinalis, showed hopeful endurance rates and, therefore, these two species control the mangrove plantations in general as mono specific stands. These species are moderate quality timbers used for fuel wood, constructions and furniture [16], [17]. Around 80\% by area of the premature plantations consisted of mono specific stands of S. apetala, about $15 \%$ consisted of stands of $\mathrm{A}$. officinalis with the residual areas consisting of Excoecaria agallocha, Bruguiera spp. and Ceriops decandra, more precious species for timber or paper pulp production. Polybag culture of a range of other mangrove species has been experimentally developed although field assessments of the performance of these species are as yet unfinished [13].

\section{Mangrove forest's link to Flood/Cyclonic Defense \\ 5.1 Importance of Mangrove Forests}

Mangrove are crucial coastal ecosystem for many tropical and sub-tropical countries [4], providing various timber and non-timber products to the coastal dwellers [11]. In spite of their economic and ecological importance, coverage and quality of the mangroves are declining in many places for various reasons [5]. According to the World Wildlife Fund [10], "the impenetrable root systems of mangrove forests lock in sediments flowing down rivers and off the land. This helps stabilizes the coastline and prevents erosion from waves and storms. In areas where mangroves have been cleared, coastal damage from hurricanes and typhoons is much more severe. By filtering out sediments, the forests also protect coral reefs and sea grass meadows from being overpowered in sediment."

\section{Case Study: Gangamatir Char}

Gangamatir Char is a small island residing in Kuakata located at $21.9861^{\circ} \mathrm{N} 90.2422^{\circ} \mathrm{E}$. [7]. It limits about 25-30 families living in the area. This particular area was selected because of its location being far away from the city and being close to the shore.

Methods: Qualitative approaches, such as indepth interviews, focus group discussions and observations were held for understanding people's responses to and the impact of a disaster. The field research compared a combination of participant observations and non-participant external interactions with coastal communities. Questionnaires included reasons for vulnerability, adaptation strategies, and pre-during and post cyclone measure. The methodology also included risk scoring which will be explained presently.

The people interviewed were first asked to draw a map of their village. They were given pen and paper but the drawings were later illustrated in the following way:

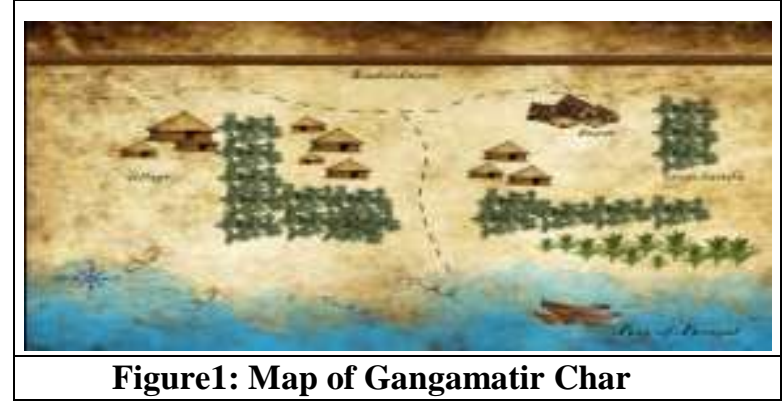

Findings: Overall the findings of this study indicated that the inhabitants were fully dependent on crops and fisheries but due to their geographical location they were prone to flood. Interviews and focus group discussions showed that apart from monsoon or rainfall floods, tidal surges occurred in the area frequently over a period of 1.5 years. They received little to no early warning because they were too far from the mainland. After cyclone Aila in 2009, an embankment in $1.6 \mathrm{~km}$ inland was built, but due to lack of permission they had to live afar from the embankment and close to the shore as shown in Figure 2. They mentioned that their vulnerability grew increasingly as the tidal surges were accompanied by wind storms and inundation.

Loss and damage: because of the aforementioned vulnerabilities and lack of cyclone shelters (only 2 cyclone shelters in the area) resulted in loss of crops, destroyed homes and deaths. As the island is away from the town, there were no clinic centers or hospitals, therefore immense number of people died while they were being taken to a nearby hospital.

Socio-economical Vulnerability: According to the local people, farmers faced the most nuisances because after the flood, their crops were destroyed and due to saline intrusion it took them months to plant new crops. Fishermen came in second rendering financial loss, after losing their homes; they had to take loans from different venders to buy 
fishing nets and boats. For calculating more vulnerability, we formulated risk factors.

Risk Factor Formula and results:

Risk Score $=$ Likelihood of occurrence*seriousness of the incident occurred.

This information was collected from the inhabitants and they responded as follows:

\begin{tabular}{|c|c|c|c|}
\hline & Seriousness & Likelihood & $\begin{array}{c}\text { Risk } \\
\text { Score }\end{array}$ \\
\hline $\begin{array}{c}\text { Tidal } \\
\text { Surges }\end{array}$ & $7 / 10$ & $4 / 5$ & 28 \\
\hline Floods & $9 / 10$ & $3 / 5$ & 27 \\
\hline Cyclones & $10 / 10$ & $2 / 5$ & 20 \\
\hline
\end{tabular}

Local and Expert Adaptation Techniques: Included embankment along the beach using stones to avoid erosion and plantation of trees. Experts suggested Village Community Fund (so loans can be avoided and vulnerabilities can be decreased) and building Artificial Sand Dunes. Relocating the locals if possible as due to Sea level Rise soon the land will be flooded by the Sea also due to climate change intensity of disasters are increasing.

\section{Conclusion and Recommendations}

As a lack of infrastructure limits the options that can be employed in tropical coastal regions such as in South-west Bangladesh to provide protection from cyclonic events,

Afforestation measures have shown great promise to not only be an effective method of protecting communities from major storm events, but also provide a steady flow of income to the struggling local economy.

However, even though the system is relatively inexpensive, it is still a complicated system to run, as the mangrove ecosystem requires careful balance - too much focus on the expansion, species diversification and strengthening of the forest due to a focus on maximizing protection and there would be no one to protect as the local economy will suffer. On the other hand, allowing the local communities to have heavy access to the mangrove forest to stimulate the local economy will lead to a vulnerable green embankment and potential for heavy property damage, not to mention unsustainable practices such as excessive resource extraction and/or focusing on specific species due to ease of access or simply being profitable "cash plants" will destroy the green embankment beyond recovery and the economy will be on the brink of destruction.

\section{REFERENCES}

[1] Alam, E., \& Collins, A. E. (2010). Cyclone disaster vulnerability and response experiences in coastal Bangladesh. Disasters, 34(4), 931-954.

[2] Cannon, T. (1994). Vulnerability analysis and the explanation of 'natural 'disasters. Disasters, development and environment, 13-30.

[3] Chaffey, D. R. \& Sandom, J. H., Sundarbans Forest Inventory Project, Bangladesh: A Glossary of Vernacular Plant Names and a Field Key to the Trees. Land Resources Development Centre, Surrey, 1985, $23 \mathrm{pp}$.

[4] Chapman, V. J. (1976). Mangrove vegetation. Vaduz.: J. Cramer, 581.

[5] Ellison, A. M. (2002). Macroecology of mangroves: large-scale patterns and processes in tropical coastal forests. Trees-Structure and Function, 16(2), 181-194.

[6] Islam, M. N. (2000). Embankment erosion control: towards cheap and simple practical solutions for Bangladesh. In 2nd International Conference on Vetiver (ICV2) (pp. 307-321).

[7] Kalapara Upazila. (n.d.). Retrieved August 28, 2017, from http://en.banglapedia.org/index.php?title=Kala para_Upazila

[8] Khatun, B. M. R. \& Alam, M. K., Taxonomic studies on the genus Avicennia Linn. From Bangladesh. Bangladesh J. Bot., 16 (1987) 39-44.

[9] Latest IPCC report confirms global warming - and human influence. (2013). Physics Today. doi:10.10363/pt.5.027274

[10] Mangrove importance. (n.d.). Retrieved August 23, 2017, from http://wwf.panda.org/about_our_earth/blue_pla net/coasts/mangroves/mangrove_importance/

[11] Mangrove forest management guidelines (English) In: FAO Forestry Paper (FAO), no. 117 / FAO, Rome (Italy). Forest Resources Div., 1994, 339 p. Accession No: 345631, Job No: T1785, Fiche No: 345631, ISBN 92-5-103445-1, ISSN 0258-6150, Call No: S238 38 ENG.ED (FOL)

[12] Ramaswamy, V., Schwarzkopf, M. D., Randel, W. J., Santer, B. D., Soden, B. J., \& Stenchikov, G. L. (2006). Anthropogenic and natural influences in the evolution of lower stratospheric cooling. Science, 311(5764), 1138-1141.

[13] Saenger, P., Assistance to the Forestry Sector of Bangladesh-Report on Coastal afforestation Research (Plantation Trial Unit): Progress Review to October 1990. 
UNDP/FAO Project BGD/85/085 Working Paper No. 38, 1990, 63 pp.

[14] Santer, B. D., Taylor, K. E., Wigley, T. M. L., \& Johns, T. C. (1996). A search for human influences on the thermal structure of the atmosphere. Nature, 382(6586), 39-46.

[15] Santer, B. D., Wehner, M. F., Wigley, T. M. L., Sausen, R., Meehl, G. A., Taylor, K. E., ... \& Brüggemann, W. (2003). Contributions of anthropogenic and natural forcing to recent tropopause height changes. science, 301(5632), 479-483.

[16] Sattar, M. A. \& Bhattacharjee, D. K., Strength properties of keora ( Sonneratia apetala ). Bangladesh Forest Research Institute, Timber Physics Series Bulletin No. 7, 1983, 6 pp.

[17] Sattar, M. A. \& Bhattacharjee, D. K., Physical and mechanical properties of sundri (Heritiera formes) and baen (Avicennia alba). Bangladesh Forest Research Institute, Timber Physics Series Bulletin No. 10, 1987, 8 pp.

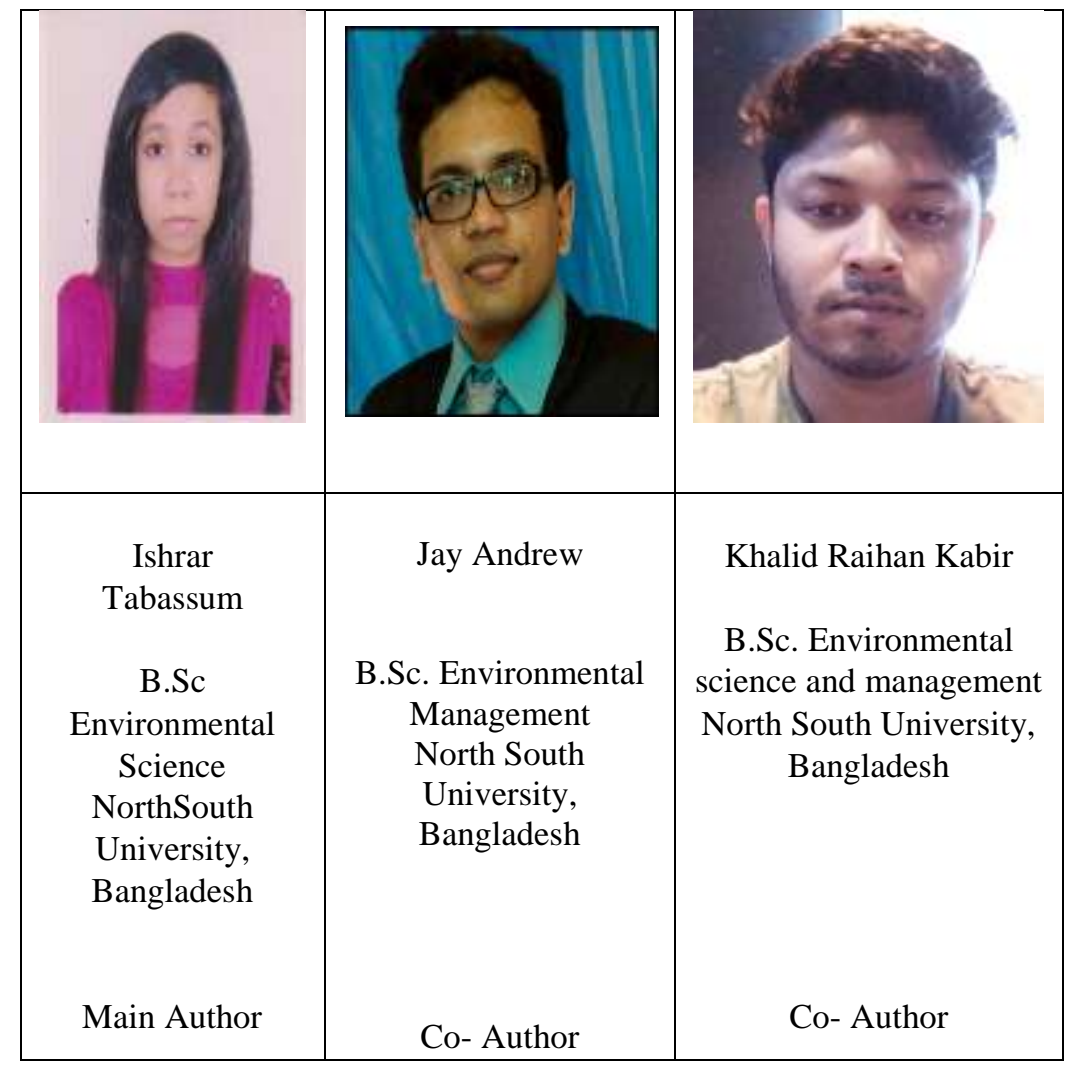

